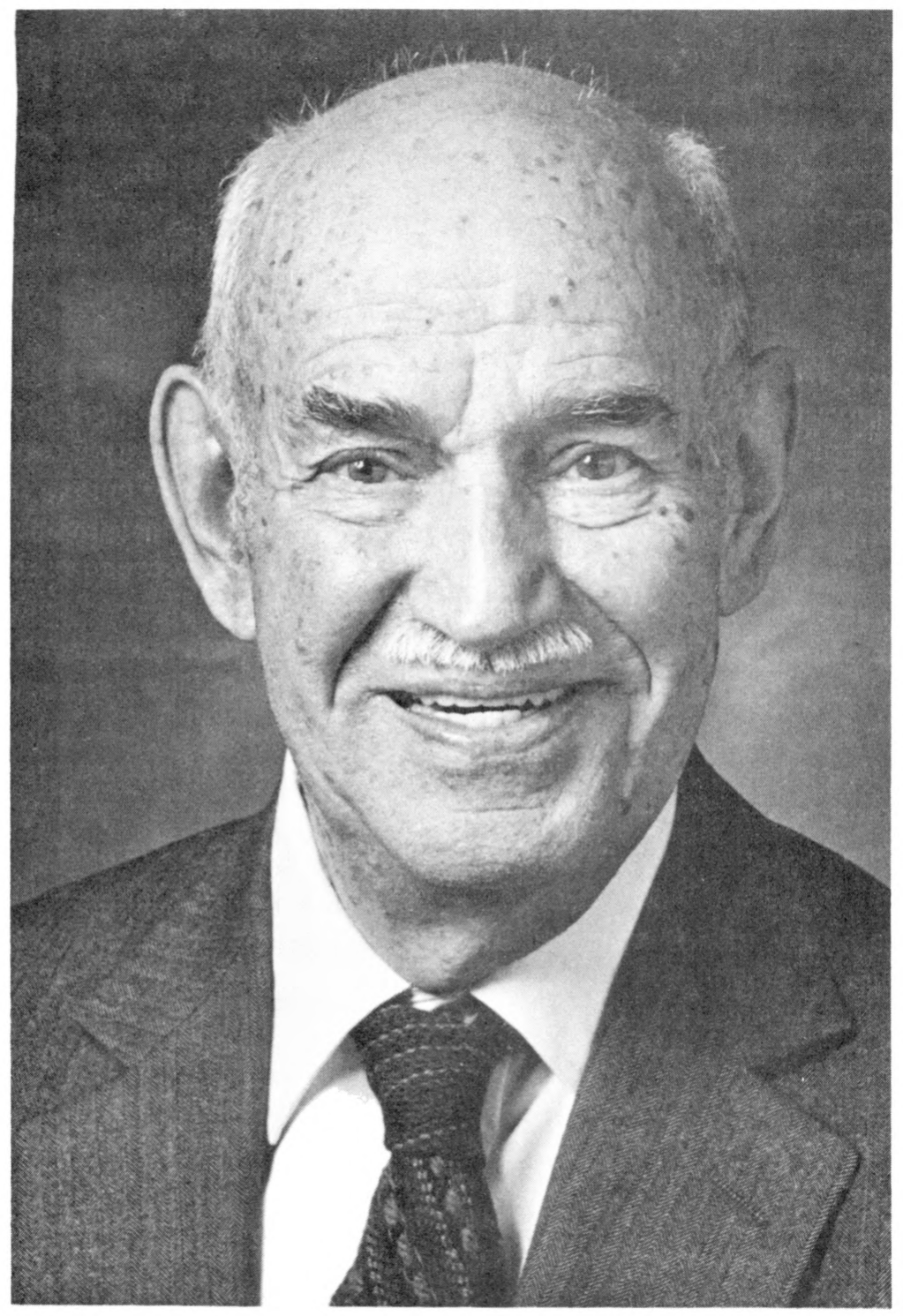

Allen Walker Read 


\section{Allen Walker Read}

\section{Kelsie B. Harder}

To praise a scholar is to face the light of eternity, to recognize the inexhaustibility of the mind, to feel the immortality of intelligence, and to glorify a worthy human. The task is no doubt impossible; the attempt enhances the praiser without depreciating the scholar or the scholarship. Many definitions of scholar exist, but, in the case here, I prefer the description found in The Talmud: "A scholar should be like a leather bottle, which admits no wind; like a deep garden bed, which retains its moisture; like a pitch-coated vessel, which preserves its wine; and like a sponge, which absorbs everything."

Allen Walker Read is a scholar, a scholar who climbs real mountains and the more realistic mountains of knowledge, and both require a physicality of mind and body that rejects moderation and compromise. His accomplishments are a matter of record and perhaps need no further praise than that the record be read and studied. But there is more. The man and the scholarship are inseparable in one sense, but in another sense they are separable. Perhaps the man can be summed up in the term gentleman, although the age of courtliness and courtesy may have become history. Still, the gentleman is just that, a gentle person. Allen Walker Read is one of the humans who can qualify easily, one whose kindness and considerateness are proverbial among those who know him. A gracious host, a warm and loving friend, a kind and gentle guide, he is a person of merit.

Here, however, I am not asked to praise the person but to comment - harsh word - on his scholarship, on his place in many disciplines, and on his contributions to the study of language. My comments will be few, though his contributions are many and far-ranging. My first knowledge of Professor Read came about when I was in a graduate class (three students) in American English grammar taught by Professor Thomas Pyles. He read to us from Read's youthful book on American epigraphy, or early American graffiti, or, as Dr. Pyles translated for us, "outhouse wall writings." Then we learned that Read, as a very young man, was a major editor of the University-of-Chicago-based Dictionary of American English, under the direction of Sir William Craigie, the editor 
of the Oxford English Dictionary, who came to the University of Chicago to edit the $D A E$. Indeed, Read's work in language had a strong effect on me and contributed greatly toward my study of language.

My first meeting with Professor Read occurred at the first Names Institute program, 1962. We did not know then that the Institute would have such pervasive influence, through its guidance by $\mathrm{E}$. Wallace McMullen, on the study of names. Read read (and puns have been made) "The 'Far West' Marches on," which contained documentary evidence of the fluid use, decade by decade, of the term, Far West. Of course, many of us at the first meeting had not heard him read a paper. This first experience was a lasting one, for when he began to read in an almost hurried but carefully modulated voice, attention immediately was riveted on the reader; and through this galvanizing of the audience's observation and alertness, the recognition of the meticulous and yet far-ranging scholarship began to emerge and literally absorb the audience. It was a performance never to be forgotten, and yet it was not in any way a staging. The intensity of the reading, coupled with the documentation from obscure sources, made the occasion most effective. Having heard him read many times since then, I still marvel at his ability to turn the reading of a scholarly paper into a work of art.

And his papers covered many subjects and reflected many disciplines. His contributions to lexicography have been noted. Other areas in which his scholarship has been apparent are dialect, American speech, semantics, linguistics, history, poetry, and probably some that have not been mentioned here. His research into the origins of $O . K$. is typical of his scrupulous and precise research, plus the arranging of documentation to come to a conclusion that should put to rest forever some of the folkish myths concerning the origin of the ubiquitous and universal term of approval. No doubt, his most ingenious paper is "The Rebel Yell as a Linguistic Problem" (American Speech, May, 1961), an analysis of the effect of the blood-curdling shriek as reported by those who heard it on the field of battle. More typical of his work, however, are "The Relation of Definitions to their Contextual Basis" (ETC, Winter, 1982), "Approaches to Lexicography and Semantics" (Current Trends in Linguistics, 1983), or "The Impact of 'Ethnicity' on Attitudes toward the English Language" (Geolinguistics, 1984).

Professor Read has worked for many years (since the 1930's) on a dictionary of Briticisms, "which will list words that are characteristic of British English by having originated in the British Isles after the founda-

Harder 
tion of the American colonies, by having senses that apply to referents in the British Isles rather than elsewhere, or having uses (meaning, frequency, or style) that are typical of the British Isles" (John Algeo, Newsletter of the American Dialect Society, 19, No. 2, Sept., 1987, 5). Read's file, according to Algeo, includes now more than 100,000 illustrative quotations collected from writings in the 19th and 20th centuries. The work was interrupted by World War II and also Read's editorship of American Speech, but the work continues and the collection has furnished material for many papers and articles. Algeo concludes, "The editing of the dictionary will doubtless take several years, but we hope to have a sample done by this time next year" (Sept., 1988).

His contributions to onomastics have been and are many, germinal, and substantial. He was introduced to the study of place names at the University of Iowa (inspired by H.L. Mencken). Then he went to the University of Missouri, where he collaborated with Robert Lee Ramsay, whose profound scholarship influenced him deeply. In 1926, Read wrote his M.A. thesis, Study of Iowa Place Names Selected from Counties A through $F$ (University of Iowa, unpublished). Since then, Read has been a leader in the field, instrumental in the initiating of the American Name Society, and credited with being among the first to suggest that a placename survey of the United States be undertaken ("The Prospects of a National Place-Name Survey for the United States," Names, 18, 1970, 201-207). Here, Read listed the problems facing those involved in the survey and also possible solutions. As the survey proceeds, his directions have been followed. One problem noted was that many disciplines - and their biases-have an interest in the survey: linguists, historians, anthropologists, geographers, cartographers, and demographers. $\mathrm{He}$ writes, "Thus the field of place-name study is interdisciplinary, but this has often meant that it is the business of no one in particular." We have met this situation to the detriment of the survey. But the suggestion that the latest electronic aids be used has been of the utmost help. The computerized lists of names generated by Roger Payne and Donald Orth of the U.S. Geological Survey have made it possible to envision the survey completed, although much work and planning still need to be done.

Besides the leadership he provided, he has also continued to write articles, read papers, and research further into onomastics. A bibliography of his articles and papers would take several pages. A few titles, however, will give an intimation of the range and, perhaps, will inspire us to persuade Professor Read to collect the papers and have them published. 
Some of the papers are theoretical; some are detailed research projects. "The Forward Sweep of American Place-Name Studies," "What Long Islanders Call Themselves: Some Documentation," "Alleghania' and 'Appalachia' as our National Name," "Gossamer Threads: A Figure of Speech for Place-Name Duplication in the United States," "Compounds with the Name Connecticut." "Semantic Dimensions of Adjectives Derived from National Names, with Special Reference to 'Un-English' and 'UnAmerican'," "The Challenge of Place-Name Study," "Walt Whitman's Attraction to Indian Place Names," "The Quality of Decisions by the United States Board of Geographic Names in Northern New York," "The Variable Application of the Topographic Term 'River'," "America's Ingratitude for its Naming: The Tribulation of Signora Vespucci," "Is the Name United States Singular or Plural," "The Bemusement of Americans over Place Names in England," "The Onomastic Component of T.S. Eliot's "The Waste Land'," "The Numerical Naming People," and the list could go on for pages. Some of these have not been published yet. He was also writing papers and reading them for other disciplines during the time he was contributing so much to onomastics.

He has been honored by many organizations and universities. He has served as President of the American Name Society, New York Folklore Society, LACUS Forum, American Dialect Society, Conference on Linguistics, The Semiotic Society of America, American Society for Geolinguistics, Dictionary Society of North America, and the Phi Beta Kappa Association of New York. He has been a consultation to the major dictionary editors in the United States. On May 11, 1985, he was awarded the degree of Doctor of Human Letters, honoris causa, by the University of Iowa, where his father was a professor of chemistry from 1913 to 1940, and where he was graduated with a Bachelor of Arts in 1925. He attended Oxford University as a Rhodes Scholar and received a B. Litt. in 1933. On January 23,1988 , he was honored with the degree of D. Litt. from Oxford University.

The essays in this issue of Names are dedicated to Allen Walker Read as a small token of our appreciation for his guidance of the Society and for his many contributions to the study of names. In every sense of the word, he is a great scholar, one who embodies all the qualities of the best of human beings. We have all been honored by knowing him.

State University College at Potsdam, New York

Harder 